\title{
Situando o pós-modernismo na perspectiva do desenvolvimento moral-cognitivo
}

Stephen Chilton ${ }^{l}$

\section{Introdução}

A crítica dos pós-modernos aos sistemas normativos é perspicaz, mas vulnerável a auto-negação reflexiva e decorrente impotência política. Este ensaio busca o simultâneo resgate e reconhecimento do pós-modernismo, situando-o como participante de uma estrutura dialética - a "ciência reconstrutiva" de Habermas - que inclui tanto a construção como a descontrução. A seqüência de estágios da argumentação moral proposta por Kohlberg é utilizada para organizar esses diversos posicionamentos teóricos.

Este ensaio apresenta um enquadramento teórico para situar o pósmodernismo. $^{2} \mathrm{O}$ marco enfatiza certas características lógicas do pósmodernismo e de várias outras posições normativas, de modo a reconhecer a força do pós-modernismo e esclarecer a maneira em que a "ciência reconstrutiva" de Habermas encontra no pós-modernismo a sua contribuição positiva, cuja

\footnotetext{
${ }^{1}$ Professor Associado de Ciência Política da Universidade de Minnesota, Duluth, Estados Unidos. Página pessoal: www.d.umn.edu/ schilton/E-mail: schilton@d.umn.edu. Agradeço aos colegas Dick Hudelson, Liz Stich, e Janelle Wilson, cujos comentários ajudaram a aprefeiçoar este trabalho. Este trabalho foi apresentado no seminário Habermas e a pós-modernidade, realizado pelos programas de pós-graduação em Ciências Sociais e em Filosofia na Pucrs nos dias 14 e 15 de junho de 2002.Tradução do inglês feita por Paulo J. Krischke, revista pelo autor.

${ }^{2}$ Supõe-se aqui a familiaridade do leitor com a seqüência de estágios da argumentação moral desenvolvida por Lawrence Kohlberg (Kohlberg 1981, 1984; Colby e Kohlberg 1987) e com a perspectiva geral da epistemologia genética de Jean Piaget (Flavell 1963). Encontra-se em Chilton (1988a) uma apresentação e explanação muito condensada desses pontos. Ver também Fishkin (1984).
} 
ausência é muitas vezes criticada. Longe de enfocar as dificuldades do pósmodernismo para desconsiderá-lo - tática que é usada ideologicamente pelas estruturas de poder estabelecidas para devolver a crítica dos pós-modernos desejo esclarecer aqui como a ciência reconstrutiva preserva a força da crítica pós-moderna, enquanto presta-lhe apoio contra a acusação de relativismo absoluto e conseqüente auto-negação.

Essa perspectiva básica é esquematizada na tabela que segue. A sociedade pré-moderna se caracteriza, em termos do desenvolvimento moral, por sua organização em relações face a face de pequenas comunidades. Os conflitos sociais são resolvidos através de acomodações mútuas entre todas as partes. A comunidade é pequena o suficiente (e organizada de modo simples o bastante) para que as relações entre as pessoas sejam basicamente face a face, de modo a saberem quais são, e com quem se fazem os seus acordos. No estágio 3, em que ocorre a "regra de ouro de primeira ordem", tais acordos são alcançados mutuamente, ao afirmar uma relação de cuidado mútuo. ${ }^{3}$

\footnotetext{
${ }^{3}$ Os estágios pré-modernos anteriores - estágios 1 e 2 - não se baseiam na reciprocidade mas no poder relativo ou na troca de vantagens, mas o ponto básico é que na sociedade pré-moderna os conflitos são sobre pessoas, relações e circunstancias específicas. Tecnicamente o estágio 3 é apenas completamente satisfatório para as relações diádicas, já que uma mudança em qualquer relação pode romper os acordos feitos com as demais relações dos parceiros. No clássico dilema moral de Kohlberg acerca de Heinz e o remédio, onde Heinz deve decidir se rouba o remédio para salvar a vida de sua esposa, entram em conflito as relações de Heinz com sua esposa e com o farmacêutico. A tragédia de Sófocles "Antígona" revela isso também, quando a relação rompida entre o rei Creonte e o rebelde morto Policines rompe as relações de Creon com Antígona (irmã de Policines), seu filho Hemon (noivo de Antígona), e sua esposa Eurídice. Esse foi meu argumento anterior (Chilton 1988a). Essa interpretação ajudou a ilustrar a natureza da ruptura de importância central entre os estágios 3 e 4, mas agora não creio mais ser essa a melhor interpretação de "Antígona". Penso que essa é uma lenda prudencial acerca das conseqüências funestas da recusa tenaz à negociação com os demais. Ou seja, penso que Sófocles considerou o problema como decorrente em primeiro lugar da inflexibilidade de Creonte, sua recusa a encontrar uma acomodação recíproca com as pessoas que o cercavam. A insolência de Creonte consistiu numa determinação unilateral de ser o único árbitro do bem e do mal naquela situação. Sua recusa de buscar acordo foi punida pela morte de sua esposa, seu filho e da futura nora. O mesmo ponto pode ser encontrado em "Édipo", outro drama de Sófocles, na interpretação da trágica falha de Édipo como uma determinação de conhecedor da verdade de sua situação, apesar dos clamores de sua mãe/esposa Jocasta - isto é, sua recusa a alcançar um acordo recíproco com ela.
} 


\section{Tabela 1:}

Estágios do desenvolvimento moral-cognitivo

\begin{tabular}{|c|c|c|}
\hline \multicolumn{2}{|c|}{ Estágio Moral } & Posições assertivas/construtivas (negrito) \\
\hline \multirow{2}{*}{ Pré-modernos } & 3 & Significado normativo surge das relações face a face \\
\hline & $31 / 2$ & $\begin{array}{l}\text { Negociações face a face tornam-se incapazes de regulamentar } \\
\text { sociedades extensas, diversificadas, complexas e interconecta- } \\
\text { das }\end{array}$ \\
\hline \multirow{5}{*}{$\begin{array}{l}\text { Modernos e } \\
\text { Pós-modernos }\end{array}$} & 4 & $\begin{array}{l}\text { Significado normativo já dado, sobreposto a relações face a } \\
\text { face específicas, deve ser sustentado. Absolutismo político e } \\
\text { religioso; conservadorismo clássico. Fascismo, nazismo. }\end{array}$ \\
\hline & $41 / 2$ & $\begin{array}{l}O \text { "já dado" das normas do Estágio } 4 \text { torna-as culturalmente } \\
\text { arbitrárias, revelando nesse ponto que a escolha existente } \\
\text { reflete o poder social. }{ }^{4} \text { Relativismo cultural, libertarianismo, } \\
\text { Hobbes [sic] }\end{array}$ \\
\hline & 5 & $\begin{array}{l}\text { Teorias de significado normativo com pelo menos igualdade } \\
\text { formal de produção de sentido. Liberalismo clássico; Kant; } \\
\text { conservadorismo Burkeano [sic] }\end{array}$ \\
\hline & $51 / 2$ & $\begin{array}{l}\text { Toda teoria de significado normativo recai no "trilema de } \\
\text { Münchhausen", e por serem arbitrárias novamente refletem o } \\
\text { poder social (como no Estágio 41/2). Teorias do pós- } \\
\text { modernismo, construcionismo social/interacisnismo simbólico; } \\
\text { Foucault, Derrida, Benhabib, Fraser }\end{array}$ \\
\hline & 6 & $\begin{array}{l}\text { Dualidade de teorias normativas e crítica: argumentação } \\
\text { dialétical ciência reconstrutiva. Tanto o significado normativo } \\
\text { como as críticas do mesmo são ainda necessários; descoberta } \\
\text { pela inescapabilidade (= universalidade na prática), de modo } \\
\text { que toda teoria corrente de significado normativo pode ser } \\
\text { suplantada pela evasão de qualquer um, quando tal evasão } \\
\text { necessitará a reconstrução da teoria para levá-la em conside- } \\
\text { ração. Ética argumentativa; Habermas. }\end{array}$ \\
\hline
\end{tabular}

A sociedade pré-moderna tornou-se moderna quando a interação social já não pôde ser regulamentada pelas relações face a face. Historicamente, isso aconteceu devido ao crescimento demográfico, processos produtivos mais complexos e conexões comerciais mais amplas, e a mudanças tecnológicas

\footnotetext{
${ }^{4} \mathrm{O}$ termo "reflete" é deliberadamente ambígüo. Pode significar que uma configuração de poder existente obrigou as pessoas a essa escolha, ou que uma escolha acidental ou pré-existente resultou numa estrutura de classes privilegiando aqueles que ocasionalmente se beneficiam dessa escolha. (Ou, é claro, ainda com ambas as consequiências). O ponto básico aqui é que a arbitrariedade moral e o poder social estão internamente conectados.
} 
mais rápidas. $\mathrm{O}$ crescimento demográfico tornou difíceis ou impossíveis as relações face a face. E o ritmo lento das acomodações face a face era vagaroso demais para adaptar-se à maior velocidade das mudanças (novos mercados, rotas de comércio, novas tecnologias e conhecimentos). Não importava que a sociedade fosse organizada nos estágios 1, 2 ou 3 de argumentação moral, já que todos eram fundados em relações face a face.

Tais problemas puderam ser enfrentados no estágio 4, quando a lealdade pessoal se organizou sob um sistema moral superposto e definido centralmente, com as relações face a face subordinadas a essa lealdade. Neste contexto a sociedade moderna aparece com o advento do verdadeiro sujeito político, o cidadão, cuja responsabilidade não é apenas obedecer a lei, mas também sustentá-la. As teorias políticas da modernidade diferem amplamente umas das outras, mas são todas mantidas pela idéia do direito e da cidadania.

O restante de nossa história se organiza pelo intercâmbio entre uma busca por fundamentação normativa e uma crítica de tal fundamentação. As posições se alternam entre posicionamentos morais positivos $(4,5$ mostrados em negrito), e subversões críticas desses posicionamentos $\left(4 \frac{1}{2}, 5^{1 / 2}\right.$, mostrados em itálico). ${ }^{5}$ Notemos finalmente que cada estágio tem várias teorias que com ele se associam, indicando uma semelhança cognitiva-estrutural entre as variações específicas de seus posicionamentos teóricos.

O pós-modernismo aparece no estágio 51/2. Esse posicionamento indica a sua característica essencial de relativização das teorias do estágio 5, ao subverter a sua pretensão de objetividade. Por exemplo, o argumento básico de Foucault é que as instituições e categorias lógicas da sociedade liberal não são neutras nem inevitáveis. Ao contrário, são sempre escolhas contigentes realizadas para favorecer um agrupamento social particular (classe, ocupação etc.). ${ }^{6}$ As críticas pós-modernas específicas diferem em como identificam e subvertem tais pretensões de objetividade, mas partilham da mesma lógica básica.

A crítica pós-moderna demonstra a força do chamado "trilema de Münchhausen", a saber, que qualquer tentativa de fundamentar uma teoria moral na

\footnotetext{
${ }^{5}$ Essas posições são numeradas conforme o esquema de estágios de Kohlberg (Colby e Kohlberg 1987). A obra de Kohlberg inclui especificamente o estágio 41ำ. A obra inclui o Estágio 6 apenas como posição teórica, pois encontrou poucos sujeitos nesse nível para estabelecer sua existência. Kohlberg nem mesmo menciona os estágios $5 \frac{1}{2} 2$ (ou 31/2), mas derivo sua existência do argumento de Fishkin (1984) de que cada um dos estágios de Kohlberg pode ser subvertido pela relativização do comando anterior. (Portanto há também os estágios $2 \frac{1}{2} 2$ e 11/2, que não aparecem na tabela). Seguindo Fishkin, não incluí um Estágio 6 1 ² , porque argumentarei adiante que o Estágio 6 incorpora a sua própria relativização.

${ }^{6} \mathrm{Na}$ verdade não é necessário pretender que tais escolhas foram feitas conscientemente; apenas que foram escolhas - ou seja, contingentes - e que seus resultados servem para favorecer arbitrariamente e portanto injustamente alguns grupos em detrimento de outros.
} 
lógica propositiva resulta sempre em uma de três situações insatisfatórias: ou a cadeia de implicações justificatórias é circular, ou redunda em uma regressão ao infinito, ou ainda interrompe em certo ponto considerado como verdade auto-evidente (Habermas 1983/1990). Esta última alternativa é objeto das críticas dos pós-modernos. Estas críticas mostram realmente que os posicionamentos "auto-evidentes" são de fato abertos à crítica, desalojando assim o teórico do estágio 5 de sua posição estabelecida.

Contudo, as críticas não se dirigem apenas à subversão de posicionamentos específicos; pois afinal crítica e reformulação são parte familiar da normalidade do debate moral. Ao contrário, as críticas pós-modernas buscam estabelecer por antecipação que todos os posicionamentos são vulneráveis. Por exemplo, a arqueologia do saber de Foucault mostra que é possível descobrir uma corrupção originária por considerações de poder, no exame das origens de qualquer prática ou categoria social. As críticas específicas de Foucault podem dirigir-se a categorias e práticas específicas - a clínica, a prisão, a sexualidade, mas o seu método pode ser aplicado universalmente. De modo semelhante, as críticas específicas de Derrida ilustram o seu método que é aplicável mais geralmente: mostrando a ênfase e privilégio de certas formas de saber e um obscurecimento (encoberto) de outras alternativas. O reconhecimento e a reversão dessas iluminações e obscurecimentos revela alternativas suprimidas cuja negligência não se pode facilmente justificar. Os campos intimamente semelhantes das teorias sócio-construtivistas e do interacionismo simbólico proporcionam críticas similares, na sua demonstração continuada de como as práticas sociais se constróem a partir das escolhas das pessoas, e podem ser portanto concebidas outras construções alternativas. Tal como as críticas pós-modernas, atacam não apenas posições específicas mas o sentido conjunto de naturalidade, sobre o qual se assentam esses posicionamentos. Pois é possível disfarçar (mas não superar) a terceira "ponta" do "trilema de Münchhausen", ao aparentar inatacável sua fundamentação final; mas o pós-modernismo remove sistematicamente esses disfarces. Argumentos semelhantes se aplicam ao ataque de Benhabib (1986) ao conjunto da abordagem das teorias fundadas na justiça (argumentando que o foco no "Outro Generalizado" exclui qualquer consideração do "Outro Concreto"), e à longa lista de Fraser (1986: 425) sobre os meios que mantêm o domínio de certos discursos normativos.

Como acontece também com os outros estágios relativizadores, a posição pós-moderna pode ser criticada, por seu relativismo crítico ignorar que o mundo segue requerendo que coordenemos nossas ações com os demais, e que as normas de coordenação exigem uma justificação que o pós-modernismo é incapaz de proporcionar. Esta crítica prática corresponde à crítica teórica acerca da auto-contradição - o argumento de que a crítica pós-moderna totalizante 
subverte sua própria capacidade de requerer que as pessoas prestem qualquer atenção às mesmas demandas que apresenta.

Tal objeção é superada no estágio 6. Os detalhes deste posi-cionamento são demasiado complexos para uma plena exposição neste espaço, mas os seguintes pontos esboçam essa posição. ${ }^{7} \mathrm{O}$ estágio 6 coloca as teorias normativas e suas críticas (pós-modernas) em relação dialética, sem reconhecer primazia nem desconhecer a nenhum dos lados, estabelecendo concessões entre ambos. A teoria normativa deve abandonar a expectativa de afirmar qualquer verdade absoluta: as posições normativas podem apenas sustentar-se como contingentes. Mesmo o acordo entre todos é contingente, já que essa unanimidade pode romper-se pela evasão de qualquer um, seja agora ou posteriormente. E em especial, as objeções pós-modernas devem ser consideradas. Contudo, o reconhecimento dessa contingência não remove a natureza vinculante de qualquer das posições que estejam apresentadas.

O pós-modernismo, por sua vez, desiste do direito de denunciar antecipadamente todas as posições. O seu método pode seguir identificando os problemas das posições normativas existentes, mas deve fazê-lo na prática. Tais críticas são aceitas e mesmo bem recebidas, mas apenas sob a forma de correções concretas post facto. Mesmo se antecipamos uma série infinita dessas correções, a posição normativa contingente retém sua força vinculante.

Esta dialética abstrata estrutura a ética argumentativa, em que Habermas deriva seu posicionamento moral dos pressupostos da argumentação. No momento colocamos entre parênteses a questão de como Habermas chega a esses pressupostos. Habermas os deriva da posição moral de que as normas são apenas justificadas quando são (ou poderiam ser) acordadas na prática por todos. Se ele identifica corretamente os pressupostos e suas deduções dos mesmos são corretas, consegue então "acuar" o cético moral a uma aceitação de seu posicionamento, porque qualquer tentativa de argumentar contrariamente a essa posição enredaria o cético numa "contradição performativa": argumentar coloca em jogo os próprios pressupostos dos quais Habermas deriva suas conclusões. Portanto, neste sentido a justificação de Habermas funda-se na inescapabilidade da ética argumentativa, e não na sua auto-evidência.

Mas como pode Habermas provar que a sua compreensão dos pressupostos argumentativos é correta? Aqui ele se volta ao que denomina "ciência reconstrutiva", uma lógica dialética em que a correção dos pressupostos argumentativos deve provar-se na prática. Se o cético for capaz de formular uma objeção ao argumento ético sem enredar-se numa contradição performativa, então os pressupostos devem ser revistos para levar em conta essa objeção, e o argu-

\footnotetext{
${ }^{7}$ Exposições mais extensa podem ser vistas em Chilton (1998) e Chilton (2000).
} 
mento ético decorrente deve ser alterado de modo correspondente. A argumentação ética é assim reconhecida como contigente, já que nunca podemos provar a exatidão dos pressupostos argumentativos - embora a menos, e até que alguém consiga contorná-los, a utilização do método da contradição performativa permita demonstrar, na prática e para todos, ${ }^{8}$ a sua correção e a do sistema moral a que apela.

\section{Referências bibliográficas}

Benhabib, Seyla (1986b). The Generalized and the Concrete Other:the KohlbergGilligan controversy and feminist theory. Praxis International, 5(4), p. 402-424, Jan.

Chilton, Stephen (1988a). Normative justification. Cap. 3 de Chilton (1988). Disponível online em: http://www.d.umn.edu/ schilton/Articles/DPD3.html

Chilton, Stephen (1988). Defining Political development. Boulder: Lynne Rienner.

Chilton, Stephen (1998). A second moment of discourse ethics. In: Felipe (1998:141153). Disponível online em: http://www.d.umn.edu/ schilton/Articles/ SMDE1998.html

Chilton, Stephen (2000). The two moments of discourse ethics Workshop outline.

UMD Political Science Department. Disponível online em: http://www.d.umn.edu/ schilton/Articles/TMDEworkshop.html

Colby, Ann e Lawrence Kohlberg (1987). The Measurement of moral judgment. New York: Cambridge University Press, 2 v.

Felipe, Sônia T. (1998). Justiça como eqüidade: fundamentação e interlocuções polêmicas (Kant, Rawls, Habermas). Florianópolis: Insular/Núcleo de Estudos em Ética e Filosofia Política.

Fishkin, James S. (1979). Tyranny and legitimacy: a critique of political theories. Baltimore: Johns Hopkins.

Flavell, John (1963).The developmental Psychology of Jean Piaget. Princeton: Van Nostrand

Fraser, Nancy (1986). Toward a discourse ethic of solidarity. Praxis International, 5(4): p. 425-429, jan.

Habermas, Jürgen (1983/1990). Moral consciousness and communicative action Cambridge: MIT.

Kohlberg, Lawrence (1981). Essays on Moral development. v. 1: The Philosophy of Moral development. New York: Harper \& Row.

\footnotetext{
${ }^{8}$ Não parece razoável que o "acordo entre todos" seja este critério. Chilton $(1998,2000)$ dedica-se a mostrar como o argumento ético pode lidar justamente com o desacordo.
} 
Kohlberg, Lawrence (1984). Essays on moral development. v. 2: The Psychology of Moral development. New York: Harper \& Row. 